\title{
Econometric modeling for energy losses and GHG emissions scenario: a governance case for toll digitalization
}

\author{
Alexey Mikheev ${ }^{1}$, Kanwar Muhammad Javed Iqbal ${ }^{2, *}$, Irina Kapustina ${ }^{3}$ and Fida Hussain ${ }^{2}$ \\ ${ }^{1}$ Moscow State Institute of International Relations (University) of the Ministry of Foreign Affairs of \\ the Russian Federation, Moscow, Russia \\ ${ }^{2}$ National Institute of Maritime Affairs, Bahria University, Sector E-8, 44000 Islamabad, Pakistan \\ ${ }^{3}$ Peter the Great St. Petersburg Polytechnic University, Graduate School of Service and Trade, \\ 195251, St. Petersburg, Russia
}

\begin{abstract}
There are growing climatic concerns of global warming due to increase of GHG emissions in the Earth's atmosphere. There is a dire need of energy conservation and GHG emissions reduction by minimizing energy losses and bringing efficiencies in all processes including the transportation sector which has a major share. The business as usual case of energy losses and emissions from road transport with manual toll system has significant impacts not only on the atmosphere but also on non-renewables' reserves and balance of payments of a country. It is a major challenge for energy sector governance and climate mitigation strategies worldwide. Thus, this paper aimed at developing econometric modeling for the assessment of various aspects and different scenarios of energy losses, emissions, BOPs and economic growth. The proposed modeling is based on multivariate Seemingly Unrelated Regression (SUR) model and can be used for informed decision-making process effectively. It will help in rationalizing the case for toll digitalization in order to accrue multiple benefits in terms of maintaining BOPs and environmental security with reduced emissions and energy losses.
\end{abstract}

\section{Introduction}

Globally, energy has become the backbone of all activities [1,2] during the Anthropocene era and is the largest contributor towards GHG emissions [3]. Climatic variations due to increased emissions have a very close nexus of energy with environmental security which is an important aspect for non-renewable resources [4]. There may be a paradigm shift due to energy insecurity [5] and its crises as a result of supply and demand gap [6]. The nonrenewable context of fossil fuel and warming effect due to its irrational burning are serious concerns regarding energy efficiency and reduction of losses in all processes. SDGs Report 2020 highlighted that the natural resources usage is unsustainable and the desired 3\% target of energy efficiency has not achieved worldwide. While, the annual global emissions reduction target is lagging to about $7.6 \%$ to maintain a pace for limiting warming effect to 1.5 [7]. There are growing climatic concerns [8] of global warming due to increase of GHG

\footnotetext{
* Corresponding author: kanwar.javediqbal@gmail.com
} 
emissions in the Earth's atmosphere. There is a dire need of energy conservation and GHG reduction by minimizing energy losses and bringing efficiencies in all processes including the transportation sector which generates a major share of emissions from $90 \%$ fossil fuel burning, comprising diesel and gasoline [9].

The business as usual case of energy losses and emissions from road transport has significant impacts not only on the atmosphere [10] but also on non-renewables' reserves and balance of payments of a country. The passenger and cargo road vehicles observe toll system at highways and motorways [11-14]. Most of the toll plaza system in the world are manual where vehicles have to be in queue and to wait from 2 to 50 seconds [11]. Thus, a big chunk of energy is lost [15] with increase in emissions at these manually operated toll plazas $[16,17]$. These two variables of manual toll system not only increase the domestic oil demand due to wastage of oil but also put pressure on country's Balance of payments (BOPs). The balance of payment, energy loss, harmful emissions, domestic oil demand, waiting time at toll plaza and international oil prices have a large impact on the economic growth of a country $[18,19]$ and vice versa. The negative impact would likely aggravate further with business as usual scenario of economic growth and particularly important for mega transnational projects such as Belt and Road Initiative (BRI) of China which has global geo-economic endeavor $[20,21]$. Therefore, the manual toll system considered a major challenge for energy sector governance and climate mitigation strategies worldwide.

Based on the problems associated with manual toll plaza system, this paper was aimed at developing methodological framework for assessing the various aspects and different scenarios of energy losses, emissions, BOPs and economic growth; through econometric modeling. This methodological modeling is based on multivariate Seemingly Unrelated Regression (SUR) or Three Stage Least Square (3SLS) models for the estimations of the relationships between dependent and independent variables. It can be used for informed decision-making process effectively, for rationalizing the case of toll digitalization in order to accrue multiple benefits in terms of maintaining BOPs and safeguarding the environment. The digitalized toll system not only reduces the waiting time at toll plaza but also minimize energy losses and harmful emissions [15] as well as relaxing pressure on BOPs. Thus, it contributes towards energy governance and environmental security by meeting emission reduction targets under UNFCCC's Paris Climate Agreement 2015.

\section{Methodology}

The state of literature shows various econometric models proposed for analysis of efficiencies in processes. These methods include Data Envelopment Analysis (DEA) for relative efficiencies [22] of the Decision Making Units (DMUs), and Vector Autoregressive (VAR) models [23], and multivariate Seemingly Unrelated Regression (SUR) method [24] or Three Stage Least Square (3SLS) models [25]. This paper used SUR Equations System for econometric modeling of the relationships between dependent and independent variables of energy losses and GHG emissions at a roadway toll system with different multivariate scenarios of business as usual and digitalized cases. The SUR models framework was selected considering its application with Stata Statistical Software or EViews [26] etc. and usage in many transportation studies [27]. A mix-method approach was applied by employing various techniques and tools prior to construct SUR Equations System, compatible with time series data, to meet the objective of this paper.

A cause and effect analysis was done through 3 consecutive focus group consultation sessions with experts' groups, by employing network analysis [28-30] based on lifecycle process approach for traffic flux [28] as shown in figure 1 and situational analysis for determining the variables [31] for econometric modeling [32,33] as shown in figure 2. 


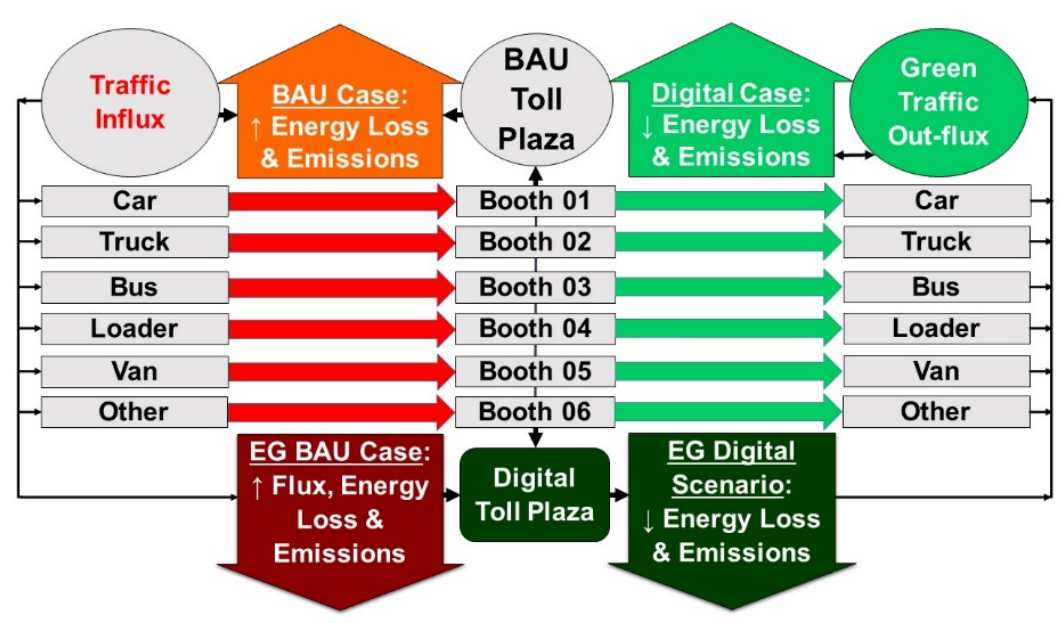

Fig. 1. Traffic Flux \& Process Flow Diagram based on Network Analysis.

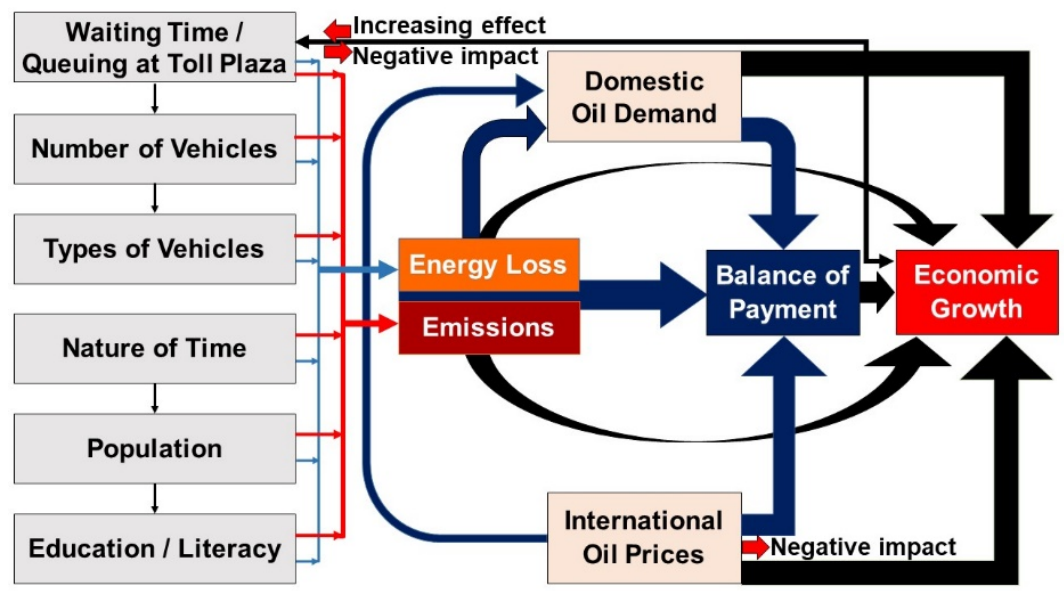

Fig. 2. Variables Flow Diagram for Econometric Modeling.

The experts evaluated the implications of energy losses and GHG emissions with three main aspects i.e. traffic influx, toll plaza and out-flux, and two different scenarios of business as usual and digitalized systems. The figure 2 consists of variables determining the relationship between dependent and independent variables in four econometric models. The diagram consists of three parts i.e. left, center and right sides. The left side of the diagram is showing the diagrammatical representation of two models.

The first model consists of the dependent variable on energy loss and the independent variables are fuel consumption due to waiting time / queueing at toll plaza, number of vehicles, types of vehicles, nature of times, population and education/literacy of the relevant actors. The second model provides representation of the GHG emission as dependent variable and independent variables including fuel consumption due to waiting time / queueing at toll plaza, number of vehicles, types of vehicles, nature of times, population and education/literacy. The center part of the figure 2 shows arrangements for the third model with balance of payment as dependent variable for independent variables of energy loss, GHG emission, domestic oil prices and international oil prices. The right side of the figure 2 consists of the fourth model with economic growth as dependent variable and energy loss, energy emission, balance of payment, domestic oil demand and international oil prices are independent variables. 


\section{Results}

Based on determined multivariate models, this section provides modeling output constructed in the form of four main econometric system of equations. The first equation is for Energy Loss/ Consumption constructed on similar trends as reported in literature [18,19,34,35] for the relationship between energy consumption and economic growth. The second equation is for GHG Emissions developed on the patterns of estimating the relationship between $\mathrm{CO}_{2}$ emissions and economic growth $[18,34,36]$. In similar fashion, the third equation derived for the Balance of Payment while the fourth equation formulated for Economic Growth.

\subsection{Seemingly Unrelated Regression (SUR) model}

The SUR model assumes that the error term across the different equations are correlated with each other and the same model was also used previously for the calculation of the relationships between systems of equations [37]. Following are the mathematical expression of newly constructed system of equations for SUR models:

$$
\begin{gathered}
E L_{t}=\gamma_{0}+\gamma_{1} W A P+\gamma_{2} N O V+\gamma_{3} T O V+\gamma_{4} N O T+\gamma_{5} P O P+\gamma_{6} E D+\varepsilon_{1} \\
E E_{t}=\delta_{0}+\delta_{1} W A P+\delta_{2} N O V+\delta_{3} T O V+\delta_{4} N O T+\delta_{5} P O P+\delta_{6} E D+\varepsilon_{2} \\
B O P_{t}=\beta_{0}+\beta_{1} E L+\beta_{2} E E+\beta_{3} W A P+\beta_{4} O D+\beta_{5} I O P+\varepsilon_{3} \\
E G_{t}=\alpha_{0}+\alpha_{1} E L+\alpha_{2} E E+\alpha_{3} B O P+\alpha_{4} W A P+\alpha_{5} O D+\alpha_{6} I O P+\varepsilon_{4}
\end{gathered}
$$

In the above equations $\gamma_{0}, \delta_{0}, \beta_{0}, \alpha_{0}$ are the constant terms of equations $1,2,3$ and 4 respectively. The EG is Economic Growth; EL is Energy Loss; EE is GHG Emission; BOP is Balance of Payment; WAP is fuel consumption due to Waiting Time / queueing at Toll Plaza; OD is Domestic Oil Demand; IOP is International Oil Prices; NOV is Number of Vehicles; TOV is Type of Vehicle; NOT is Nature of Time; POP is Population, and Ed is the Education. Whereas, the $\gamma_{s}$ indicates the coefficients of the energy loss equation. The $\delta_{s}$ shows the coefficients of the GHG Emissions equation. The $\beta_{s}$ represents the coefficients of Balance of Payment. While the $\alpha_{s}$ reveals the coefficients of economic growth equation. The $\varepsilon_{1}, \varepsilon_{2}, \varepsilon_{3}$, and $\varepsilon_{4}$ indicate the error term of equations 1, 2, 3 and 4 respectively. While $\boldsymbol{t}$ is showing the Time Period. The variable construction process used dependent, independent and control variables for SUR system of equations. The following subsections explain each variables based on their nature.

\subsection{Equation 1}

Energy loss / energy consumption [18] is dependent variable for first model which can be calculated from average fuel consumption during waiting time at toll plaza. The independent variables are waiting time of a vehicle at toll plaza; number of vehicles passed from a toll plaza; types of vehicles, and nature of time. The waiting time is the variable for an average time spent by a vehicle while paying toll tax. It can be calculated in terms of minutes and seconds. The number of vehicles shows the total vehicles passed through a toll plaza during a specific time interval which can be counted per day / month / or year and be classified into various types (i.e. cars, trucks, bus, van, loader, other etc.) against the nature of vehicles. Nature of time is last independent variable for the vehicles passed through a toll plaza for which calculation can be done on the basis of peak, normal and minimum flux for a particular toll plaza. The control variables consists of the size of population, and education / literacy of the relevant actors including drivers. The size of population can be calculated as the average 
population in the area of traffic flux. The education/literacy can be calculated with the criteria of having a valid vehicle license and knowledge about traffic rules.

\subsection{Equation 2}

The energy emission [19] is the main dependent variable for the second model which may be calculated through the average GHG emissions during the wait time at a toll plaza, based on emission factors for different types of fuels used by various category vehicles. The independent variables for the second model are the waiting time of a vehicle at toll plaza; number of vehicle passed from toll plaza; types of vehicles, and nature of time. The control variables consist of the size of Population, and education/literacy of the drivers.

\subsection{Equation 3}

The Balance of payment $[38,39]$ is the main dependent variable for third model. The balance of payment can shows the amount of foreign exchange reserves. It can be calculated on the basis of monthly foreign exchange reserves of a country. The independent variables of the third model consist of Energy loss and GHG emissions. The control variable consists of Domestic Oil Demand and International Oil Price. The domestic oil demand shows the country's overall oil demand. It can be calculated from the import bill of oil reserves. The international oil price is also a control variable for the study. The variable can be calculated on the basis of prevailing oil prices at the international oil market.

\subsection{Equation 4}

The Economic growth $[18,19,34-37]$ is the main dependent variable in $4^{\text {th }}$ model. The economic growth can be calculated through percentage increase in GDP. Further, the GDP growth will further consider the monthly percent change in the industrial production for the study period. The independent variable of the fourth model consists of Energy loss, GHG Emissions and Balance of Payments. The control variable consists of Domestic Oil Demand and International Oil Price. Some features of the systematic approach should be taken into account $[40-42]$.

\section{Discussion}

The application of Seemingly Unrelated Regression model (SUR) is widely practiced and it can help in informed decision-making process for energy and environmental security. During the study, the case of a manual toll plaza is found a very important governance challenge for energy losses, GHG emissions and BOPs. Globally, there are various factors involved behind keeping the manual toll system intact. It may be due to lack of awareness about its impacts on national economy and global warming, transparency, corruption and resource constraints in national, sub-national and local governance context. It is anticipated that this novel SUR System of Equations can be employed effectively to rationalize the digitalization of business as an usual case of manual toll system, by demonstrating it as a good governance case. It may be used in E-Views, Stata Statistical Software, R-Package etc. with time series data to determine the multivariate relationships. The model can explain the current state of the energy loss, GHG emissions and Balance of Payments based on the historical data. It will provide reliable results with the appropriateness of the model for the calculation of system of equations. The results of all the four equations can be interpreted clearly. 
The first equation will provide information about dependence of BOPs and GHG emissions due to energy loss at toll plaza. The model indicates a strong relationship between the waiting time at toll plaza and energy loss. It means that when there will be increase in waiting time for the vehicles then it will lead to more usage of oil and gas resources thus more energy will be lost. The model also anticipates direct relationships between number of vehicles, the energy loss and GHG emissions. The energy loss is also dependent on the types of vehicles. Equation 1 also shows that the vehicles passing at peak flux timings will consume more energy and vice versa thus having a linear relationship between energy loss and emissions. The equation of equation 1 also provided the depended of energy loss on the population of urban areas which means that more urbanization will lead to more energy consumption at toll plaza. The population rise will pose negative impact due to energy loss. It is expected that education of driver will have a strong relationship with energy loss.

The second equation provides dependence of GHG emissions on the waiting time at toll plaza, number of vehicles, type of vehicles, nature of time, population, educations. The first independent variable i.e. waiting time at manual toll plaza has a direct relation with GHG emissions meaning that the rise in the waiting time will cause increased emissions to the atmosphere. In equation 2, GHG emissions have a strong relationship with number and types of vehicles and their timing to pass through a manual toll plaza. Equation 2 also takes into account the traffic flux and may be used for forecasting scenarios with change in demographic patterns under the areas of influence for manual toll plazas. It means that increase in the population of an area will lead to more demand of vehicles thus cause more emissions. The equation 2 also shows an inverse relationship between the education/literacy and emissions. It is evaluated that the digitalized toll system will reduce the GHG emissions with smooth and uninterrupted traffic flow for all types of demographic scenarios.

The third equation modeled the dependence of BOPs on the energy loss, GHG emissions, waiting time at toll plaza, domestic oil demand and international oil prices. Equation 3 shows the direct linkages between BOP and energy loss. It means that when the energy loss will increase then it leads more pressure on the country's foreign exchange reserves. The more pressure on foreign exchange will lead to devalue the domestic currency. Equation 3 also shows that the BOP is also dependent on the GHG emissions. It shows a direct relationship between balance of payment and energy emission. Rise in GHG emissions will create financial burden due to additional fiscal requirement for climate mitigation action thus linked with BOPs. The last variable of equation 3 shows a direct relationship between international oil prices and BOPs due to energy losses and GHG emissions at manual toll system.

The last equation 04 reflects an inverse relationship between the economic growth and energy loss, GHG emissions and economic growth, and economic growth and BOPs; with very serious implications on Gross Domestic Product (GDP) of a country. It also shows an indirect relationship between waiting time at toll plaza and economic growth. Furthermore, it also establishes an indirect relationship between the international oil prices, economic growth and BOPs.

The current study has constructed a novel theoretical model but its practical application would determine its effectiveness though it is envisaged a very good system of equations for rationalizing decision-making process and help in devising a digitalized monitoring system. So, a case study may be carried out with of the application of this econometric model to evaluate its effectiveness.

\section{Conclusion}

The business as an usual case of energy losses and emissions from road transport with manual toll system has significant impacts not only on the atmosphere but also on non-renewables' reserves and balance of payments of a country. It is a major challenge for energy sector 
governance and climate mitigation strategies worldwide. Globally, there are various factors involved behind keeping the manual toll system intact. It is anticipated that this novel SUR System of Equations can be employed effectively to rationalize the digitalization of business as an usual case of manual toll system, by demonstrating it as a good governance case. The model will be able to explain the current state of the energy loss, GHG emissions and Balance of Payments based on the historical and current data source. It may also be used for forecasting scenarios with change in demographic patterns under the areas of influence for manual toll plazas. It will provide reliable results with the appropriateness of the model for the calculation of system of equations. The results of all the four equations can be interpreted clearly. This paper deciphers that the digitalized toll system will reduce the GHG emissions with smooth and uninterrupted traffic flow for all types of demographic scenarios.

\section{References}

1. M.T. Johansson, Energy Efficiency 8, 713 (2015)

2. G. Wernet, C. Mutel, S. Hellweg, and K. Hungerbühler, Journal of Industrial Ecology 15, 96 (2011)

3. M. Hassan, M. Khan Afridi, and M. Irfan Khan, International Journal of Green Energy 16, 510 (2019)

4. M. Hassan, M. K. Afridi, and M. I. Khan, Energy and Environment 29, 184 (2018)

5. M. Hassan, M. I. Khan, M. W. Mumtaz, and H. Mukhtar, Energy and Environmental Security in Developing Countries (Springer International Publishing, Cham, 2021)

6. H. Bilal, M.I. Khan, and C. Siwar, Science, Technology and Development 37, 19 (2018)

7. U.N. Statistics, Division 68 (2020)

8. K. M. J. Iqbal and M. I. Khan, Policy Perspectives 15, 139 (2018)

9. L.A.M.B. Metz, O.R. Davidson, P.R. Bosch, R. Dave, 863 (2007)

10. E. Uherek, T. Halenka, J. Borken-Kleefeld, Y. Balkanski, T. Berntsen, C. Borrego, M. Gauss, P. Hoor, K. Juda-Rezler, J. Lelieveld, D. Melas, K. Rypdal, and S. Schmid, Atmospheric Environment 44, 4772 (2010)

11. L.C. Edie, Journal of the Operations Research Society of America 2, 107 (1954)

12. S. Hernandez, A. Monzon, N. Sobrino, and S. Hernández, System (2013)

13. K. Nagabhushan and V. Katti, International Journal of Computer Science and Mobile Computing 3, 414 (2014)

14. Y. Wang, Advances in Computer Science Research 76, 1344 (2017)

15. P.H. Tseng, D.Y. Lin, and S. Chien, Technological Forecasting and Social Change 86, 265 (2014)

16. Y. Xu, C. Wang, Y. Zheng, Z. Sun, and Z. Ye, Sustainability (Switzerland) 12, 1 (2020)

17. C.S. Bari, Y.V. Navandar, and A. Dhamaniya, Journal of Hazardous, Toxic, and Radioactive Waste 24, 05020003 (2020)

18. M.M. Albiman, N.N. Suleiman, and H.O. Baka, International Journal of Energy Sector Management 9, 361 (2015)

19. U. Al-Mulali, H.G. Fereidouni, J.Y. Lee, and C.N.B.C. Sab, Renewable and Sustainable Energy Reviews 22, 209 (2013)

20. K.M.J. Iqbal and B.B. Haider, Polaris- Journal of Maritime Research (P-JMR) 3, 21 (2020)

21. A. Waheed, T.B. Fischer, and M.I. Khan, Environmental Management 18 (2021) 
22. I. Ali and K.M.J. Iqbal, Abasyn Journal of Social Sciences 10, 232 (2017)

23. F.O. Anetor, C. Ogbechie, I. Kelikume, and F. Ikpesu, Journal of Economics and Sustainable Development 7, 131 (2016)

24. A. Zellner, Journal of the American Statistical Association 57, 348 (1962)

25. K. Zaman, Environmental Science and Pollution Research 25, 4479 (2018)

26. K.K. Sumer, Applied Econometrics and International Development 12, 63 (2012)

27. M. Sheng and B. Sharp, Transportation Research Part A: Policy and Practice 124, 55 (2019)

28. M.G.H. Bell and Y. Lida, Transportation Network Analysis (2010)

29. S.P. Borgatti, A. Mehra, D.J. Brass, and G. Labianca, Science 323, 892 (2009)

30. B. Wellman, Sociological Theory (Wiley, 1983)

31. M.R. Syed and S.N. Syed, Handbook of Research on Modern Systems Analysis and Design Technologies and Applications (2008)

32. P.L.H. Immers and S. Logghe, Traffic Flow Theory (Katholieke Universiteit Leuven, 2003)

33. J. Kianfar and P. Edara, Procedia - Social and Behavioral Sciences 104, 430 (2013)

34. H. T. Pao and C.M. Tsai, Energy 36, 685 (2011)

35. Y.U. Glasure and A.R. Lee, Resource and Energy Economics 20, 17 (1998)

36. F. Halicioglu, Energy Policy 37, 1156 (2009)

37. S. Asongu, G. El Montasser, H. Toumi, Environmental Science and Pollution Research 23, 6563 (2016)

38. D. Yazdanfar, P. Öhman, International Journal of Managerial Finance 11, 329 (2015)

39. K.S. Nell, International Review of Applied Economics 17, 249 (2003)

40. S.Y. Barykin, I. V. Kapustina, T.V. Kirillova, V.K. Yadykin, Y.A. Konnikov, Journal of Open Innovation: Technology, Market, and Complexity 6, 16 (2020)

41. S. Y. Barykin, I. V. Kapustina, S. M. Sergeev, V.K. Yadykin, Journal of Open Innovation: Technology, Market, and Complexity 6, 16 (2020)

42. O. Kalinina, S. Firova, S. Barykin, I. Kapustina, Development of the Logistical Model for Energy Projects' Investment Sources in the Transport Sector (Springer Verlag, 2020) 